Journal Of Al Azhar University Engineering Sector

Vol. 12, No. 42, January, 2017, 121-129

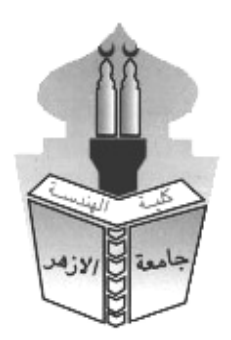

\title{
SOUNDSCAPE EXPERIENCE AND ITS IMPACT ON THE IMAGE OF ALEXANDRIA
}

\author{
Yasser Farghaly, Fahd Hemeida, Amal Mamdouh and Amr Atef \\ Architecture \& Urban Design, Arab Academy for Science, Technology and Maritime \\ Transport, College of Engineering and Technology, Alexandria, Egypt
}

\begin{abstract}
Image of the city has recently been the object of several reflections, both theoretical and empirical, in a wide range of different areas of knowledge. One might say that a new upsurge of research, of a multidisciplinary orientation, on the modes of representation of the cities was started with Kevin Lynch science 1960. Thus, to the more conventional analysis provided by city planning, architecture and landscape science, as well as by urban marketing research, was added the contribution of the social sciences, from history to anthropology, from geography to sociology. At present, the 'image of the city' is essentially an object of transversal analysis, productively traversed by so many cross-fertilizing disciplinary perspectives. The purpose of this research is to consider a particular perspective on those images - the sound image of the cities - seeking to draw attention to the way in which the social sciences, most particularly sociology and geography, approach them and include them in the body of knowledge they produce in order to consider the analytical value of sonorities and their relationship with behaviors and urban social life and environments through doing some measurements of the existing situation of Alexandria and comparing it with the international standards.
\end{abstract}

\section{Keywords: Soundscape, Sonic Environment, Acoustic Environment}

\section{INTRODUCTION}

The soundscape concept was first introduced as an approach to rethink the evaluation of noise and its effects on the quality of life. Now it has improved into something much more. Soundscape suggests exploring all of the sound in an environment in its complexity, duality, meaning, and context. The soundscape concept considers the conditions and purposes of its production and perception. So it is necessary to understand that the evaluation of sound is a holistic approach. This is why soundscape research represents a shift in the field of environmental sound evaluation. In this research the light shed on soundscape and its importance in making people able to guess and relate different sounds with different settings. This study could not be reliable without doing some sound level measurements to compare the Alexandria's sound level with the standard average.

The soundscape approach enhances the use of available resources through the local expertise of the particular environment's inhabitants. It is important that physical noise criteria with perception being the leading factor. As a result, we can better match the people's needs with planned design scheme. For example, in the community noise field, we can correlate 
complaints of people living in a certain place with metrics for policy. In the architectural design field, we can create a built environment which aligns the designer's aesthetic vision and the users 'comfort, effectiveness and sense of well-being. This process also has its parallels in the field of sound recording and musical composition. Concerning interdisciplinary, the methods of psychology and sociology, to engineering and design analyses are introduced to guarantee the combination of perceptual and physical tools for the planning of a multitude of land uses and building structures. Soundscape technique uses a variety of investigation techniques, taxonomy, and measurement methods, questionnaires, interviews and recordings (Schafer, 1994).

\subsection{Soundscape definition}

The definition of soundscape: An environment of sound with emphasis on the way it is perceived and understood by the individual, or by a society. It thus depends on the relationship between the individual and any such environment as shown in figure 1 . The term may refer to actual environments, or to abstract constructions such as musical compositions and tape montages, particularly when considered as an artificial environment. (Truax, 2001). The soundscape of the world is changing. Modern man is beginning to inhabit a world with an acoustic environment radically different from any he has known. These new sounds, which differ in quality and intensity from those of the past, have alerted many researchers to the dangers of an indiscriminate and imperialistic spread of more and larger sounds into every corner of man's life. Noise pollution is now a world problem. It would seem that the world soundscape has reached the top of vulgarity in our time and many experts have predicted universal deafness as the ultimate consequence unless the problem can be brought quickly under control (Schafer, 1994).

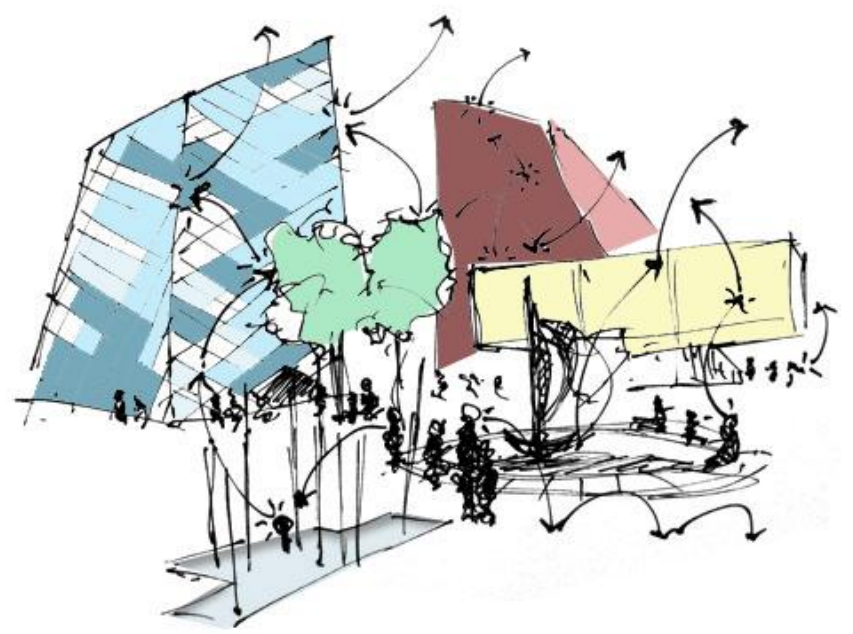

Figure 1 Soundscape diagram shows the relationship between the individual and environment (Researchers, 2016)

In the late 1960s, Canadian composer and music educator Murray Schafer first proposed the concept of soundscape as the landscape caught by ears and acoustic scenery, the concept broadened the scope of landscape (Li, 2005). Soundscape is the subject of acoustic ecology and refers to both the natural acoustic environment consisting of natural sounds, including animal and sounds from trees, the sounds of water, weather, and environmental sounds created by humans through musical composition, sound design, and other human activities, including sounds of mechanical origin resulting from the use of industrial technology. Soundscape is relative to the "visual landscape" that is more widely known, and it reveals the 
significance of sound environment in the overall urban landscape system. Soundscape researches cover not only natural environment factors, but also social, environmental, ecological and historical factors. For urban environment in particular, the soundscape construction based on natural and social factors is an essential content of urban landscape design. Soundscape design is to associate messages carried by various sounds with such elements as living environment, psychological and physical needs, receptive ability of people and society, and neighboring environment's ability of absorbing the sounds using scientific and aesthetic means, on the basis of the structures and characters of the sounds. It is to balance these elements, create and fully use value of the sounds, and design the sound actively, so the viewers will be able to see, and also to hear the landscape (WU Jialing, 2015). Different terms have been used to describe soundscape field, including the acoustic environment (Truax, 2001), the sonic environment (Schafer, 1994), the sound environment (Kihiman, 2001), sound variation (Kihiman, 2001), the environment of sound (Truax, 2001), auditory environment (Turner, 2003), auditory scenery (Ge, 2003), aural space (SchulteFortkamp, 2002), the natural acoustic environment and environment sounds (Domingo, 2007), sound ambient environments (Raimbault, 2005), ambient conditions (Raimbault, 2005), and the acoustic soundscape (Kihiman, 2001). Their definitions are summarized below in table 1 .

Table 1 Interpretation for "Soundscape" and its study (Researchers, 2015)

"The sonic environment. Technically, any portion of the sonic Sonic Environment environment regarded as a field for study." (Truax, 2001)

"Soundscape is defined as the overall sonic environment of an area, from a room to a region." (Porteous, 1985)

"The term soundscape refers to the total ambient acoustic environment within an area." (Domingo, 2007)

"The term "soundscape" can be defined as the auditory environment within which a listener is immersed." (Turner, 2003)

"Soundscape refers to the auditory scenery, the scenery that can be grasped by ears." (Ge, 2003)

"Soundscape is understood as a socio-cultural event in view of people living in a society in a particular era form relations with their environment through sounds." (Lawrence Finegold, 2006)

Acoustic Environment

Ambient acoustic environment

Auditory Environment

Auditory Scenery

Sound Environment

"Soundscape is about relationships between the ear, human beings, sound environments, and society." (Zhang, 2007)

\section{SOUNDSCAPE SOURCES}

The noise source that impacts the largest numbers of city dwellers is road traffic far exceeding the numbers impacted by noise from aircraft, heavy or light rail or industry. On the other side, people tend to be more tolerant of road traffic noise at moderate levels and consider it to be inherently less annoying than aircraft or railway noise of the same average sound level. However, above certain quite frequently-exceeded levels, traffic noise begins to limit the use and enjoyment of our homes and communities and negatively affect our health and quality of life.

Soundscape research started early. In 1930, the Noise Abatement Commission of New York made clear that the soundscape of the city is no longer dominated by sounds of animals and humans but by noise from new modern technology sources (Brown, 1930). Edward Brown et al. conducted a noise survey in1930. This survey was distributed via the metropolitan 
newspaper. Responses submitted by readers confirmed that the vast majority of noises that plagued New Yorkers were caused by modern technological inventions.

Edward Brown et al. (1930) categorized city noise sources according to the presence and location of the noise source, as well as activity performed. Thus, the categories came in the form of traffic, transportation, building operation, homes, streets, harbor and river, collection and deliveries, as well as miscellaneous sources as shown in figure 2.

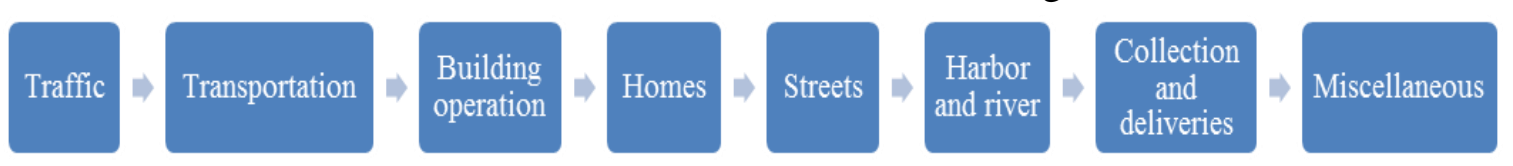

Figure 2 soundscape sources (Researchers, 2016)

The investigation of the relation between the listener and the environment has shown that audible safety is an important aspect of sound that is first evaluated early in the processing of auditory information. In particular the combined interpretation of the dimensions of core affect and the appraisal of soundscapes yields four qualitatively different types of soundscapes: Lively, Calm, Boring, and Chaotic, these four soundscape types, which can be classified according to their relative pleasantness and eventfulness, as well as according to the complexity of action selection and the content of audible affordances as shown in figure 3 .

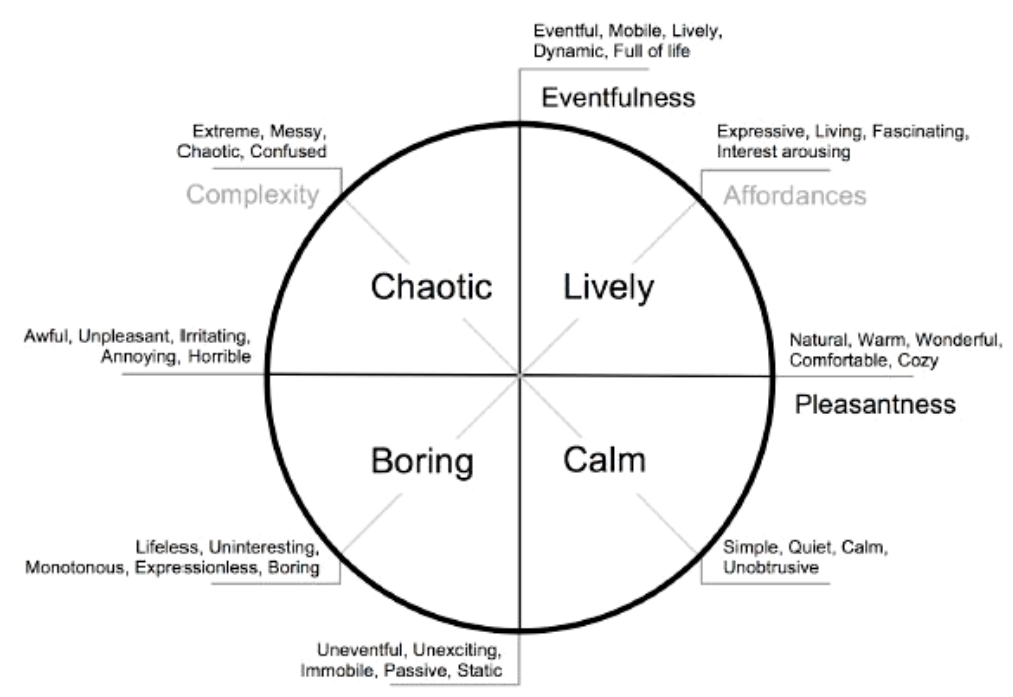

Figure 3 four types of soundscape (Andringa, 2013)

\section{Case Study (Comparative analysis)}

Comparison between Alexandria and Indian cities by measuring sound levels in different areas and comparing it with the international standards levels to assess the current conditions of both cities.

\subsection{Sound level evaluation of Indian cities}

The noise status of growing urban centers of the country are very much required to develop acoustic design and planning guidelines for various land use classification. An effort in this direction has been made by measuring noise equivalent levels for cities like Delhi, Jamshedpur, Dehradun and Nagpur (PANDYA, 2001). 


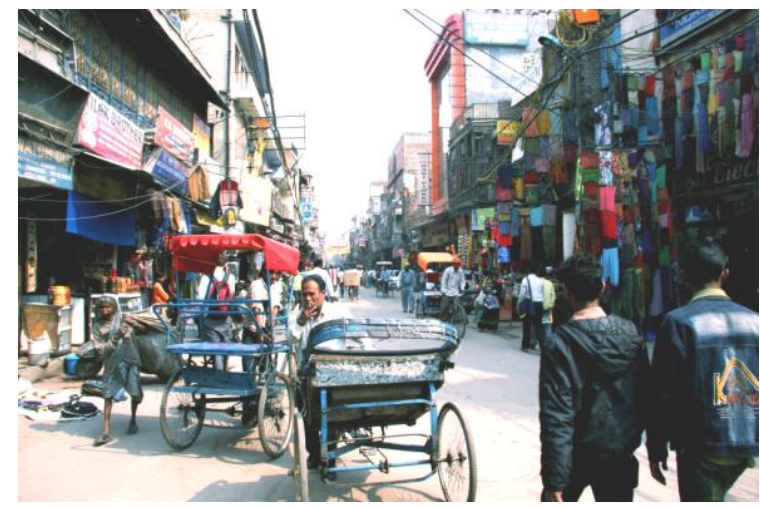

Figure 3 Street Life of New Delhi (antematters, 2012)

\subsubsection{Introduction to ambient noise standards}

Concern about the protection of the environment has grown rapidly as it has become generally recognized that steady rise in pollution of all kinds cannot be allowed to continue indefinitely. The acoustic environment has likewise suffered from the increase in use and power of the machines in the workplace, increasing road traffic, larger aircrafts etc. To combat this, many countries have introduced legislation making it a legal requirement to measure noise levels to reduce noise from vehicles at the source and maintain acceptable noise levels in factories to prevent hearing loss. India has emerged as a fast developing country resulting in an increase in activity of the workforce. In 1989, Central Pollution Control Board (CPCB), announce the Ambient Air Quality Standards for Noise as shown in table 2. The noise limits for residential, commercial, industrial and silence zone areas for assessing the urban noise problem and suggesting the mitigation measure, a look is required for environmental noise management as well it is necessary to identify levels required to protect public health (PANDYA, 2001).

Table 2 Ambient noise standards (CPCB) (Modified by the researchers, 2016)

\begin{tabular}{|c|c|c|c|}
\hline \multicolumn{4}{|c|}{ Ambient noise standards (CPCB) } \\
\hline \multirow{2}{*}{ S no. } & Area & \multicolumn{2}{c|}{ Noise level, Leq (dBA) } \\
\cline { 3 - 4 } & & 75 & 70 \\
\hline A & Day time & Night time \\
\hline B & Commercial & 65 & 55 \\
\hline C & Residential & 55 & 45 \\
\hline D & Silence Zone & 50 & 40 \\
\hline
\end{tabular}

1) Day time is reckoned in between 6 am to $9 \mathrm{pm}$.

2) Night time is reckoned in between $9 \mathrm{pm}$ to $6 \mathrm{am}$.

3) Silence zone is defined as areas up to $100 \mathrm{~m}$ around such premises as hospitals, educational institutions and courts.

4) Mixed categories of areas should be declared as one of the four above mentioned categories by the Competent Authority and the corresponding standard shall apply.

The noise equivalent level Leq was measured continuously (Indian Standard Institution) at each urban centre using precision integrated sound level meter, Brüel and Kjaer Model 2231. Continuous Leq measurement during day time 06:00 am - 21:00 pm. and night time 21:00 pm - 06:00 am was carried out in residential, commercial industrial and silence zone location of Delhi, Jamshedpur, Dehradun and Nagpur centres. The Leq results of each location were then 
used to calculate the Day and Night noise levels Ldn. This model has been applied to the various urban centers for assessing the noise climate (PANDYA, 2001).

\subsubsection{Results and analysis}

The average noise equivalent level Leq for the day and night time for various locations covering cities like Delhi, Dehradun, and Nagpur.The Leq varies from 55-80 dBA (Day) and 48-72 dBA (Night) at Delhi, 58-80 dBA (Day) and 52-69 dBA (Night) at Jamshedpur, 54-77 dBA (Day) and 45-66 dBA (Night) at Dehradun, and 53-76 dBA (Day) and 44-70 dBA (Night) at Nagpur, respectively (PANDYA, 2001) as shown in figure 4. It is observed that Leq exceeds the CPCB limits for most of the locations. When environmental noise from a particular area is considered, it is the noise emanating from multiple sources such as construction, transportation, commercial and domestic activities. Because of the activity status of a particular area, Leq varies for residential, commercial, industrial and silence zone areas. Results could be concluded as shown in table 3 .

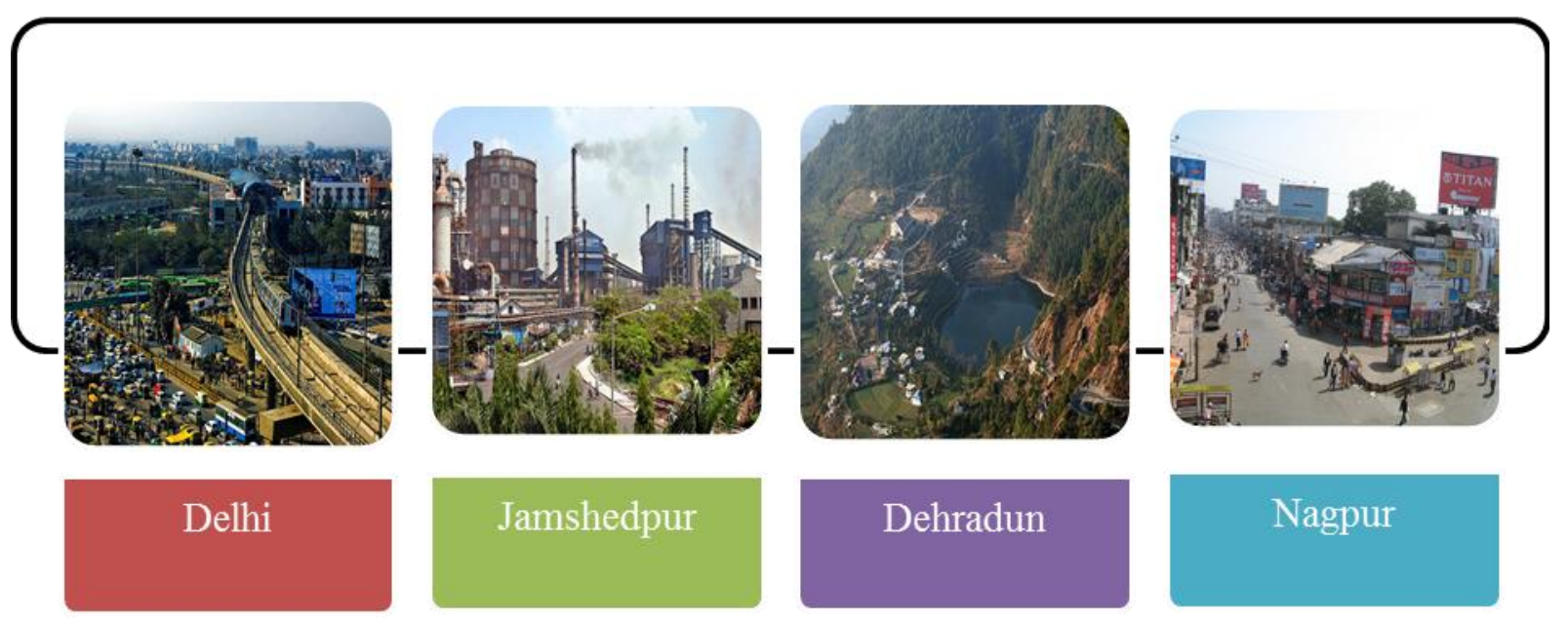

Figure 4 places of field study in India (Researchers, 2016)

Table 3 sound level measuring criteria (Researchers, 2016)

\begin{tabular}{|c|c|c|c|c|c|c|c|c|c|c|}
\hline \multicolumn{11}{|c|}{ Sound level measuring criteria } \\
\hline \multirow[t]{2}{*}{$\begin{array}{l}\text { S. } \\
\text { No. }\end{array}$} & \multirow[t]{2}{*}{ Area } & \multicolumn{2}{|c|}{$\begin{array}{c}\text { Sound level, } \\
\text { Leq (dBA) } \\
\text { (Measured) } \\
\text { average }\end{array}$} & \multicolumn{2}{|c|}{$\begin{array}{l}\text { sound level } \\
\text { Leq (dBA) } \\
\text { (Standard) } \\
\text { According } \\
\text { to land use } \\
\end{array}$} & \multicolumn{3}{|c|}{$\begin{array}{l}\text { sound level Leq (dBA) } \\
\text { (Standard) }\end{array}$} & \multicolumn{2}{|c|}{ Evaluation } \\
\hline & & day & night & day & night & Area & day & night & acceptable & $\begin{array}{c}\text { Not } \\
\text { acceptable }\end{array}$ \\
\hline 1 & Delhi & 75 & 72 & 55 & 45 & Industrial & 75 & 70 & - & $\mathbf{X}$ \\
\hline 2 & Jamshedpur & 72 & 66 & 75 & 70 & Commercial & 65 & 55 & -- & $\mathbf{X}$ \\
\hline 3 & Dehradun & 66 & 60 & 65 & 55 & Residential & 55 & 45 & -- & $\mathbf{X}$ \\
\hline 4 & Nagpur & 57 & 54 & 50 & 40 & Silence Zone & 50 & 40 & -- & $\mathbf{X}$ \\
\hline
\end{tabular}

\subsection{Sound level evaluation of Alexandria}

The noise status of growing urban centers of the country are required to develop acoustic design and planning guidelines for various land use classification. An effort in this direction has been made by measuring noise levels for Alexandria using Brüel \& Kjær model 2239 as shown in figure 5 . 


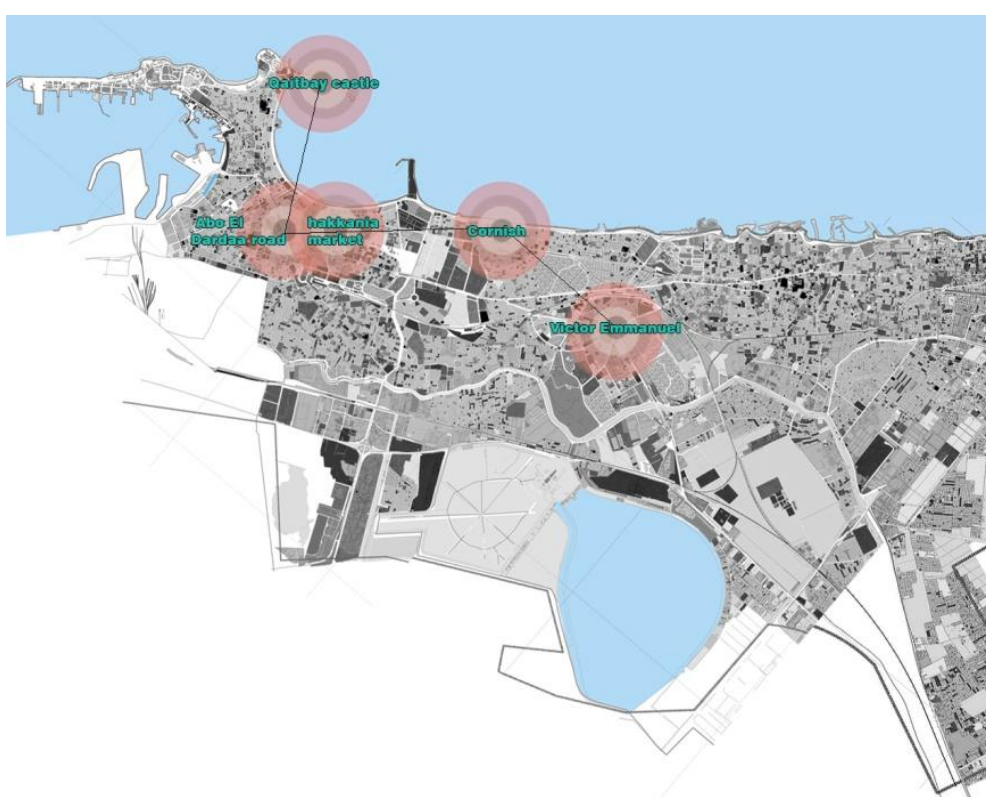

Figure 5 Places of field study in Alexandria (Researchers, 2016)

\subsubsection{Results and analysis}

The average noise equivalent levels Leq for the day and night time for the five locations that represent the city image principles (landmark, path, edge, district, and node) covering Alexandria. 14 measurements have been taken for each place and the results came as the following, the Leq varies from 72-106 dBA (Day) and 65-88 dBA (Night) at the piazza of Qaitbay castle in Alexandria which represent city landmark as shown in figure 6.

The Leq varies from 78-93 dBA (Day) and 79-106 dBA (Night) at Abo El Dardaa road in Alexandria which represent city path. The Leq varies from 65-110 dBA (Day) and 86-108 dBA (Night) at Cornish road in Alexandria which represent city edge. Measurements show that the Leq varies from 72-101 dBA (Day) and 71-99 dBA (Night) at the area of hakkania market which represent city district. The Leq varies from 88-107 dBA (Day) and 80-101 dBA (Night) at Victor Emmanuel square which represent city node. It is observed that Leq exceeds the standard limits for most of the locations. When environmental noise from a particular area is considered, it is the noise emanating from multiple sources such as construction, transportation, commercial and domestic activities. Because of the activity status of a particular area, Leq varies for residential and commercial zone areas as shown in table 4 .

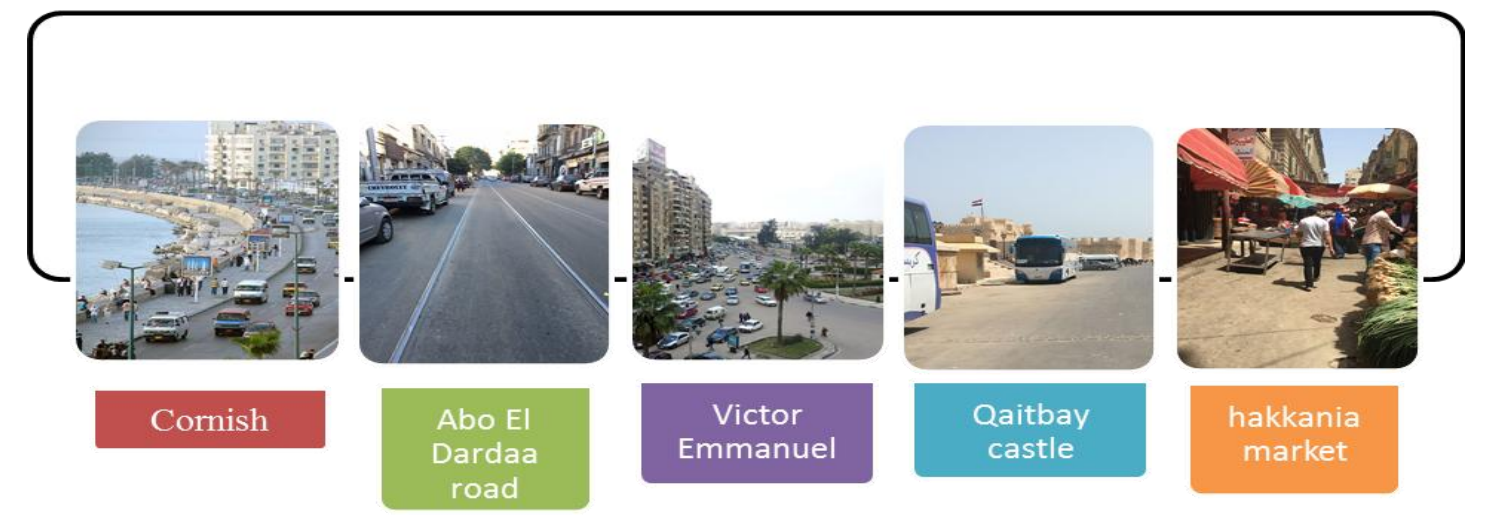

Figure 6 the five locations that represent the city image (researchers, 2016) 
Table4 sound level measuring criteria in Alexandria (Researchers, 2016)

\begin{tabular}{|c|c|c|c|c|c|c|c|c|c|c|}
\hline \multirow{3}{*}{$\begin{array}{l}\text { S. } \\
\text { No. }\end{array}$} & \multicolumn{10}{|c|}{ Sound level measuring criteria in Alexandria } \\
\hline & \multirow{2}{*}{ Area } & \multicolumn{2}{|c|}{$\begin{array}{l}\text { Sound level, } \\
\text { Leq (dBA) } \\
\text { (Measured) } \\
\text { average }\end{array}$} & \multicolumn{2}{|c|}{$\begin{array}{c}\text { Sound level } \\
\text { Leq (dBA) } \\
\text { (Standard) } \\
\text { According to } \\
\text { land use } \\
\end{array}$} & \multicolumn{3}{|c|}{$\begin{array}{l}\text { Sound level Leq (dBA) } \\
\text { (Standard) }\end{array}$} & \multicolumn{2}{|c|}{ Evaluation } \\
\hline & & day & night & day & night & Area & day & night & $\frac{\frac{0}{0}}{\frac{\pi}{0}}$ & 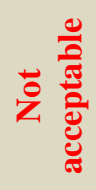 \\
\hline 1 & $\begin{array}{l}\text { Qaitbay } \\
\text { castle }\end{array}$ & 89 & 77 & 65 & 55 & Industrial & 75 & 70 & -- & $\mathbf{X}$ \\
\hline 2 & $\begin{array}{l}\text { Abo El } \\
\text { Dardaa }\end{array}$ & 86 & 93 & 65 & 55 & Commercial & 65 & 55 & -- & $\mathbf{X}$ \\
\hline 3 & Cornish road & 88 & 97 & 65 & 55 & Residential & 55 & 45 & -- & $\mathbf{X}$ \\
\hline 4 & $\begin{array}{l}\text { hakkania } \\
\text { market }\end{array}$ & 87 & 85 & 65 & 55 & Silence Zone & 50 & 40 & -- & $\mathbf{X}$ \\
\hline 5 & $\begin{array}{c}\text { Victor } \\
\text { Emmanuel }\end{array}$ & 98 & 91 & 55 & 54 & & & & -- & $\mathbf{X}$ \\
\hline
\end{tabular}

\section{CONCLUSION}

In this research the light shed on soundscape and its importance in making people able to guess and relate different sounds with different settings. This study could not be reliable without doing some sound level measurements to compare the Alexandria's sound level with the standard average the result shows that Alexandria exceed the standards of sound levels. This research highlighted the importance of soundscape which could be a tool for generating and remembering the image of the city. By the end of my study, this research can confirm and recommend the reliability of soundscape. It becomes a magical tool which differs from the traditional ones. We have to take into consideration the importance of soundscape by making it an essential tool for recognizing the city and reducing noise sources.

\section{REFERENCES}

- Antematters. (2012, july 16). antematters. Retrieved august 9, 2016, from antematters: www. antematters.com

- Brown, E. (1930). City Noise Department of Health. New York.

- Domingo, Q. J. (2007). The soundscape experience. 19th International Congres on Acoustics. madrid.

- Dubois, D. G. (2006). A cognitive approach to urban soundscapes: using verbal data to access everyday life. ACTA ACUSTICA UNITED WITH ACUSTICA 92, 865-874.

- Ge, J. a. (2003). Research on the formation and design of soundscape of urban park: case study of Saga Prefecture Forest Park, Japan," in International Symposium of city planning. Japanese society of urban planning, (pp. 139-148). Sapporo, Japan.

- Kihiman, T. a. (2001). Soundscape support to health. A cross-disciplinary research programme,. International congress and Exhibition on Noise Control Engineering. Hague, Netherlands. 
- Lawrence Finegold, M. S. (2006). Socio-cultural soundscape concepts to support policies for managing the acoustic environment. Acoustical Society of America , 120125.

- Li, C. (2005). Preliminary analysis of soundscape design. Liaoning University of Technology , 46-48.

- PANDYA, G. H. (2001). URBAN NOISE - A NEED FOR ACOUSTIC PLANNING. Environmental Monitoring and Assessment 67 , 379-388.

- Pauline, 0. (2005). Deep listening: A composer's sound practice. Lincoln, NE, New York: iUniverse.

- Porteous, J. D. (1985). Soundscape. Journal of Architectural Planning Research 2/3 , 169-186.

- Raimbault, M. a. (2005). Urban soundscapes: Experiences and knowledge. cities 22 , 339-350.

- Schafer, R. M. (1994). The Soundscape: Our Environment and the Tuning of the World. Vancouver: Destiny Books.

- Schulte-Fortkamp, B. (2002). The meaning of annoyance in relation to the quality of acoustic environments. Noise \& Health $4,13-17$.

- Truax, B. (2001). Handbook for Acoustic Ecology. Vancouver: ARC Publications.

- Turner, P. M. (2003). Evaluating soundscapes as a means of creating a sense of place. international Conference on Auditory Display. Boston, MA, USA.

- WU Jialing, Y. X. (2015). soundscape design of old urban residential districts . landscape research , 1-3.

- Zhang, M. a. (2007). Towards the evaluation, description, and creation of soundscapes in urban open spaces. Environment and Planning B: Planning and Design 34, 68-86. 